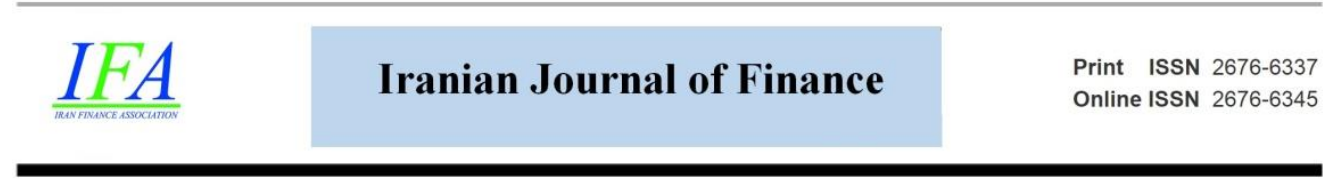

\title{
Exchange Rate Movements and Monetary Policies: Which Has Greater Influence on Petroleum
}

\author{
Shahram Molavi Bisetoni \\ Department of Industrial Management, Kish International Branch, Islamic Azad \\ University, Kish Island, Iran. (Email: shahrammolavi1350@ yahoo.com)
}

Kiamars Fathi Hafshejani*

*Corresponding Author, Assistant Prof., Department of Management, South Tehran Branch, Islamic Azad University, Tehran, Iran. (Email: fathikiamars@yahoo.com)

\begin{abstract}
Aboutorab Alirezaei
Associate Prof., Department of Management, South Tehran Branch, Islamic Azad University, Tehran, Iran. (Email: eng.m_alirezaei@yahoo.com)
\end{abstract}

\section{Ghanbar Abbaspour Esfadan}

Assistant Prof., Department of Management, South Tehran Branch, Islamic Azad University, Tehran, Iran. (Email: gh_abbaspour@azad.ac.ir)

Document Type: Original Article

Received: 2020/12/03 Accepted: 2021/02/01

2021, Vol. 5, No. 1. 147-172

Published: 2021/02/03

\begin{abstract}
The primary purpose of this study is twofold: Firstly, using the Markov Regime Switching model throughout December 2008 to February 2020, it investigates and compares the nonlinear impacts of exchange rate movements and monetary policies on Petroleum Stock Index, PSI, in Iran. Accordingly, some control variables, such as OPEC oil price, inflation rate, and international sanctions, have also been used to model these relationships more accurately. Secondly, it is an empirical attempt to trace the historical changes in the PSI behavior through distinguishing the precise regime numbers, and the relationships between the exogenous variables and the PSI. Our results confirm that the effects of both exchange rate movements and monetary policies on the petroleum stock market return are direct and significant. More interestingly, the more we move from regime one to regime three, the greater the effects of the research variables on the index, except for the impact of OPEC oil prices. Our empirical findings further suggest as the effects of sanctions intensify, the
\end{abstract}


influences of monetary policy and exchange rate movements would have a more significant impact on the petroleum stock index returns.

Keywords: Petroleum Stock Index, Exchange Rate, Monetary Policy, Markov Regime Switching Model.

JEL: C32, E52, F31, G11.

DOI: $10.30699 /$ iif.2021.125534

Copyright: author(s)
Publisher: Iran Finance Association

Type of License: Creative Commons License (CC-BY 4.0)

\section{Introduction}

The essential goal of this article is an empirical analysis of the dynamic relationship between exchange rate movements and monetary policies with petroleum stock index, PSI, in Iran. The importance of this issue can be understood by reviewing the stylized facts and status quo of both this industry and Iran economy. Firstly, in Iran economy, the stylized facts confirm the significant dependence of Iran economy to the revenues comes from the export of oil and its derivatives, thanks to its comparative advantage in massive proved oil and gas reservoirs (Heidari et al., 2019). Moreover, the "Five-Year Economic, Cultural, and Social Development Plans" of Iran for 2016-2021 as well as its other strategic plans clearly emphasize the comprehensive support for the petroleum industry in the upstream documents of Iran. Besides, based on Article 44 of the Iranian Constitution, the shares of almost all of the active petroleum companies are listed on the Tehran Stock Exchange (TSE) (Khosrowzadeh et al., 2020). As a result, to monitor the performance of this industry, the PSI in the TSE would be the right and easy to access choice. Therefore, apart from the problems caused by the resource curse phenomenon, such potentials have made petroleum industry as a leading industry in Iran, which is usually chosen as strategic investment destinations by different multinational companies (Hajiebrahimi Farashah et al., 2020). Thus, studying the effects of various essential factors on its fluctuations seems reasonable for assorted groups of people.

Secondly, the status quo of the petroleum industry indicates that like different industries in the TSE, the PSI has experienced a highly volatile period and set various new records, especially in the second half of 2020. Considering experimental evidence and tracking the macroeconomic indicators in Iran economy can support the idea that such new records in the TSE indexes have mainly rooted in two different reasons: Firstly, attracting liquidity accumulated through years of expansionary monetary policies to the stock markets (as 
excess demands); secondly, being affected by the foreign exchange rate fluctuation. It should not be overlooked that there are some other factors have escalated the instabilities of the PSI that are: (i) rising global prices of petroleum products, (ii) the nature of being export-oriented of these products and high profitability expectations owing to its exports, (iii) more demand for buying these companies' shares than their supply, and finally (iv) the reasons have enhanced the systematic risk in Iran (Zarei, 2020; Khosrowzadeh et al., 2020; Shavvalpour et al., 2017; Komijani et al., 2013). Thus, pondering about the causes of fluctuations in PSI confirms not only has the impacts of exogenous factors on the changes in this index been undeniable, but it was significantly more in some periods as well. At least, to analyze and control the roots of the movements in the PSI, the current conditions of Iran's economy would corroborate the importance of the exogenous factors.

Based on these arguments, the fundamental question is which exogenous factors have had the most significant impact on the fluctuations of the economy and the petroleum industry index as well? Examining different indicators of Iran's economy demonstrate that the roots of many of the country economic problems can be traced to factors such as international threats and ineffectual macroeconomic policies (Heidari et al., 2019). More clearly, during the USA. maximum pressure policy fulfilled through multilateral economic sanctions, Iran government budget deficit has exponentially enhanced and, in response, expansionary monetary policies (mostly, money supply growth) have become the primary, possible, and short-term solution for the authorities. The main consequence of this policy has been monetization of the budget deficit that has culminated in further fluctuations in different industries, financial markets, etc. A statistical comparison of the growth rate of liquidity in 2019 by the end of 2020 with the average growth rate of liquidity in the last four decades in Iran confirms this issue. Besides, the foreign exchange market fluctuations have not been just a reaction to the domestic macroeconomic policies, particularly the monetary one. Strictly speaking, there are different situations in which the exchange rate changes can be considered as an impulse of exogenous shocks and manifested its significant side effects ${ }^{1}$. Historically, the major foreign exchange rate shocks in Iran occurred during the years of 1988-1990, 1994$1995,2012-2013,2018-2020$ that its effects strongly affected other markets as

1 e.g. when expectations of investors are negatively affected, relative prices of tradable and non-tradable goods are significantly changed, destabilization of the financial system occurs, the efficiency of macroeconomic policies and the status of international trade balance of the economy is strikingly questioned, etc. (see Branson, 1983; Kurov and Stan, 2018). 
well (Zarei, 2020). Therefore, being among the main exogenous determinants of the economy's fluctuations, it seems necessary to study the simultaneous, comparative, and dynamic effects of these factors on the financial markets and especially the PSI.

In fact, monetization of budget deficits, simultaneously, exchange rate movements influenced by international sanctions brig about the national currency devaluation. This phenomenon, through assorted macroeconomic channels like production costs, net profits, aggregate demands, and so forth, leads to stock market fluctuations. To be more precise, not only has PSI, as an export-oriented industry, affected by domestic monetary policy ramifications, but it has impacted through exchange rate movements as well. In such a circumstance, the effects of oil price, international sanctions and inflation could not be ignored. In line with this, by reviewing the related studies listed in the literature review section, it would be clear that there are some previous studies investigated the link between either monetary policies or exchange rate fluctuations and stock market responses. However, there is no domestic and international empirical investigation exist comparing and analyzing the effects of monetary policy and foreign exchange market movements on the PSI in Iran, so far. Hence, scrutinizing and comparing the impacts of these exogenous shocks on the petroleum stock index can give macro-and micro-level decisionmakers a deep insight into real status quo of the industry and, consequently, control the ramifications of these shocks. To this aim, we use a Markov Regime Switching model ${ }^{2}$ based on the monthly time-series data of the research variables from December 2008 to February 2020.

In the following, in order to a deeper and better understanding of the study critical issue and addressing the pivotal questions of the investigation, subsequently the theoretical framework and literature reviews, data and methods, results and discussion, and finally conclusion parts will be delineated.

\section{Literature Review}

\footnotetext{
2 The crucial reason for applying Markov Regime Switching (MRS) model is the PSI severally changed behavior. Indeed, taking a glance on the PSI graph on page 9 illustrates that the PSI has different breakpoints which could be modelled through regime change approaches. On this basis, we choose MRS model to analysis how much the PSI behavior has changed during research period together with how the relationship between independent (and control) variables and the PSI has been changed in each various regimes.
} 
Stock markets, theoretically, can reflect the potential opportunities of an economy, facilitate effective resource allocation and mobilization, affect aggregate demand, and promote economic growth through changing the quality and quantity of investments (Tiryaki et al., 2018). Accordingly, controlling and understanding the roots and consequences of stock market fluctuations have always been a matter of investigation for researchers and also micro and macro decision-makers. To support this idea, studies about analyzing the effects of macroeconomic variables on stock market returns that were, firstly, conducted by Fama (1970) and Ross (1976) are, generally, referred as the theoretical base of this field. In this regard, a significant number of empirical studies have been conducted, especially in recent decades (Dahmene et al., 2021; Heidari et al., 2020; Kurov and Stan, 2018; Gong and Dai, 2017; Bahmani-Oskooee and Saha, 2016; Chatziantoniou et al., 2013; Bjornland and Leitemo, 2009). However, the decisive point here is that in different conditions, periods, and case studies, the role of some factors may become an essential issue for analysis. As demonstrated, the primary purpose of this study is to analyze the effects of monetary policy and exchange rate movements on the returns of petroleum companies active in the TSE. Therefore, this section presents the theoretical and empirical background of the relationships between independent and dependent variables of the research.

\section{Petroleum Stock Index in Iran}

First of all, it is essential to provide a brief background of the petroleum industry and explain the status and importance of this export-oriented and basic industry in Iran. On the one hand, energy as an essential input in different production process and consumption activities promotes economic growth in various countries. In this regard, the results of many studies demonstrate that the volatile nature of the global energy market can significantly affect different industries and financial markets like stock market indexes (Basher et al., 2012). Moreover, the comparative advantage of the energy market and its related industries has been undeniable for the economy of Iran because of its geographical location, proved oil and gas natural resources, diversity of the petroleum products, and supportive macroeconomic policies of the country (Shavvalpour et al., 2017). On the other hand, reviewing the exports of petroleum which its status is among the non-oil export items in Iran, show that despite the pressures of the sanctions against Iran, the export of this product has been able to account for a higher share of the country's total non-oil exports, especially in the last five years. More precisely, the percentage of petroleum companies' exports has enhanced from about 35\% in 2015 to more 
than $50 \%$ in 2019 (Saadati et al., 2020). These conditions have led to the fact that in early 2020, more than a third of the top 50 companies operating in the TSE are petroleum companies. This evidence not only confirms the status and importance of this industry but the need to delve into the effects of various factors on the performance of this industry in Iran. Furthermore, such a position and importance has led many researchers to analyze the performance of this industry and its nexus with other variables. Accordingly, some pertinent studies that have the most content similarity with the present study (mainly in the case of Iran) include Khosrowzadeh et al., 2020; Saadati et al., 2020; Zare, 2020; Hajiebrahimi Farashah et al., 2020; Honarmandi et al., 2019; Heidari, 2018; Shavvalpour et al., 2017; Abbasi et al., 2015.

\section{Monetary Policies and Stock Market}

The efficiency of monetary policies impacts on the real sectors of an economy (e.g. petroleum industry, stock market, etc.) is the main objective and concern of monetary authorities all around the world (Ansari \& Sensarma, 2019). In this regard, since the stock market is known as a significant channel for transmitting the effects of monetary policy to the real sectors, providing the theoretical ties of this issue seems instructive. On the one hand, as Mishkin (2001) asserts there are some transmission channels through which different industries of an economy will be permeated by the monetary actions that are debt instruments (i.e. interest rate) or assets prices (i.e. stock prices). Moreover, based on the findings of Laopodis (2013), the impacts of monetary policies can be appropriately transmitted into an economy through consumption channel, interest rate channel, and wealth effect channel. Besides, Ioannidis and kontonikas (2007) claim that investment spending and consumption are, generally, the critical links between stock markets and real sectors of an economy. They also confirm the effectiveness of these transitional channels in analyzing the impacts of monetary policy actions on stock prices. This claims can also be supported by Tobin-q's ${ }^{3}$ and Modigliani's life cycle ${ }^{4}$ models (Suhaibu et al., 2017).

On the other hand, Chami et al. (1999) postulate that the effects of monetary policy are transmitted to the economy primarily through the asset

\footnotetext{
${ }^{3}$ Tobin-q's model confirms that there is a direct significant relationship between stock prices and investment spending (Miskin, 2001).

4 The life cycle model proposed by Modigliani posits that there is a direct significant connection between the consumers' lifetime resources and stock prices (Miskin, 2001).
} 
price adjustment rather than through the money and credit channel. This way, they conclude that the stock market channel can be considered as an alternative transmitting channel for monetary policies. In line with this, based on a multicountry study, Chatziantoniou et al. (2013) conclude that due to the role of the stock market in promoting different sectors of an economy, considering the stock market as an alternative transitional channel has also been considered in recent literature. All in all, through monitoring the stock market performance, not only can monetary authorities assess the effectiveness of the effects of adopted monetary policy, but it also gives them a deeper insight into evaluating the changes in the future expectations of the various industries (or private sectors) in response to an expansionary or contractionary policy (Bjornland and Leitemo, 2009; Laopodis, 2013). Therefore, the significant role stock market as one of the transmitting channels of the monetary policies' effects on the real sectors is theoretically indisputable.

Fundamentally, there are some interesting viewpoints about the relationship between monetary policy and stock price. Friedman (1956) claims that any increase in the money supply cannot necessarily stimulate the real sector of an economy and also increase stock prices because the imbalance between supply and demand in the money market can be compensated by the conditions in the real sector. However, Fama (1981) believes that expansionary monetary policies are generally inflationary by nature; as a result, such policies might lead to a decrease in stock prices. In opposition to Fama (1981), Monetarism and Keynesian argue that stock market indexes can be directly affected by monetary actions. Monetarists believe that an expansionary monetary policy can enhance the stock prices by increasing the demand for equities as a result of enriching the optimum money balances. Keynesians point of view gives credence to the idea that an expansionary monetary policy, whether through increasing money supply or falling in interest rate, leads to a rise in the stock index (Suhaibu et al., 2017). All in all, both effects are supported in the empirical literature.

Empirically, the literature review corroborates the significant effects of monetary policies on different indexes in stock markets. On that account, some previous studies have only analyzed does the stock market channel play a significant role in transmitting the effects of monetary policy? whether the relationship between these variables is significant, and how can the results of such researches provide management solutions to investors and policymakers? (see Bernanke, 1995; Mishkin, 2001; Ioannidis and Kontonikas, 2007; Bjornland and Leitemo, 2009; Chao et al., 2011; Chatziantoniou et al., 2013; Laopodis, 2013; Ricci, 2015; Suhaibua et al., 2017; WooPark et al., 2019; Olli- 
Matti, 2020), while it has been necessary for researchers, in many recent studies, to pay more attention to the nonlinearity of these relationships (see Challe and Giannitsarou, 2014; Zare and Azali, 2015; Kurov and Stan, 2018; Yola, 2019; Cloyne et al., 2020; Thanh et al., 2020; Tiryaki et al., 2020; Dahmene et al., 2021).

\section{Exchange Rate Movements and Stock Market}

Some theoretical and empirical grounds support the significant relationship between exchange rate movements and different industries in the stock markets, especially the export-oriented ones, e.g. the petroleum industry.

Based on the theoretical foundations, the stock market index and exchange rate nexus can be supported by two models that are flow- and stockoriented hypothesis (Tiryaki et al, 2019). Introduced by Dornbusch and Fisher 1980, the flow-oriented model supports the significant causality from exchange rate movements to stock prices, e.g. the PSI. In this case and based on macroeconomic point of view, the PSI index depicts the discounted present value of this industry's expected future cash flows; consequently, if any exogenous variable affects this cash flow, its impacts will be reflected in the PSI. These conditions exist when there is no reason to reject the efficient markets hypothesis. Under such circumstance, if there is a currency depreciation in a country, as a result of creating an increase in trade competitiveness, its production, aggregate supply, and profitability would enhance that would culminate in an increase in its stock returns, especially in the export-oriented industries.

The concept of the stock model, however, which is compatible with portfolio balance model, is developed by Branson et al. 1983 and Frankel (1983) and, generally, claims that although endorse the significant impacts of exchange rate fluctuations on the stock market, corroborate the existence of a negative connection between the two variables based on the capital account transactions. On this basis, as the price of domestic stocks rises, investors are motivated to sell their foreign assets and, in return, increase their domestic assets like buying stocks. With the growth in demand for domestic currency, the exchange rate will decrease, and the purchasing power of local currency will enrich, which means an increase in the price of domestic assets and the wealth of investors. If this situation continues over time, more capital flows and foreign investments will be attracted and culminate in an appreciation of the domestic currency (Salisu et al., 2020).

In addition to the theoretical ties for the relationship between exchange rate movements and the petroleum stock index in Iran and because this type of 
issues has always been of interest to investors and policymakers, there are a significant number of domestic and international studies that empirically confirm the effects of exchange rate changes on the performance of such an industry in the stock markets. However, the perspectives and analytical methods of different related studies have not been the same. Accordingly, the dominant approach of almost all previous researches had been on analyzing the significance and magnitude of exchange rate effects (see Phylaktis and Ravazzolo, 2005; Basher et al., 2012; Abbasi et al., 2015; Gong, 2017; Bermudez Delgado et al., 2018; Singhal et al., 2019; Hsueh, 2020). Nevertheless, several recent studies have been conducted on the type and changes in the relationship between exchange rate fluctuations and various stock market indices (see Bahmani-Oskooee and Saha, 2016; Jung et al., 2019; Khosrowzadeh et al., 2020; Salisu, et al., 2020; Saadati et al., 2020; Tiryaki et al., 2020; Zarei, 2020).

\section{Research Hypotheses and Contributions}

Based on the theoretical and empirical backgrounds, the main concerns of this study are as follow:

1. The impacts of monetary policy on the PSI is positive and significant.

2. The effects of exchange rate on the PSI is positive and significant.

3. Monetary policy has more significant influences on the PSI than the exchange rate.

4. To address these hypotheses, we use a Markov Regime Switching model that involves both nonlinearity and structural (regime) changes. In the next section, a brief theoretical framework of this model is presented.

In line with the essential concerns of the study, there are some contributions:

1. Analyzing simultaneous effects of monetary policy and exchange rate movements on Iran PSI

2. Considering control variables based on Iran economic structure like inflation rate and oil price

3. Applying a model, Markov Regime Switching, capable to estimate different equations for each distinctive period, separated based on either breakpoints or the behaviour changes of the dependent variable.

4. Regrading to the international sanctions in using the model which could be able to match the different major historical events by the time series data. 


\section{Data and Methods}

In this study, the monthly data of "Petroleum Industry Stock Index" ${ }^{5}$ (LPSI), the "Exchange Rate" (LEXR) ${ }^{6}$, "liquidity volume" (LLQ) ${ }^{7}$, "OPEC Oil Price" (LOIL), "Inflation Rate" (LINF), and "International Sanctions against Iran" $(\mathrm{S})^{8}$ has been applied to model the relationship of the variables in the period from December 2008 to February $2020^{9}$. To have better insight into the issue, before addressing the methodology, analyzing the historical movements of all variables can give a signal for more accurate modelling of relationships between the variables. In this regard, at first glance, the PSI figure illustrates two various turning points interestingly representing the first imposed sanctions against Iran nuclear plan and the United States withdrawal from the $\mathrm{JCPOA}^{10}$. The same can be seen in the other variables graphs ${ }^{11}$. This phenomenon divides each variable chart into three various sections. This can be a convincing reason to apply switching type models in this investigation. Take a closer look at the charts, from 2008:12 to 2012:07, the PSI, EXR, and LQ have stable and slightly ascending trends, while the OIL has the volatile and considerably rising trend. In this period, the INF has u-shaped behavior. In the following period, from 2012:07 to 2018:07, the PSI, EXR, and LQ have strictly increasing behavior, although after adopting the JCPOA in July 2015, the growth rate of PSI has been slightly lower than before the time. However,

5 This is the dependent variable and gathers from the official website of Tehran Stock Exchange (www.irbourse.com).

${ }^{6}$ EXR and LQ are the independent variables and collect from the Statistical Center of Iran official website (www.amar.org.ir).

${ }^{7}$ monetary policy representative

${ }^{8}$ The international sanction variable is a dummy time series on which one represents the periods of imposed sanctions and zero for others. In this investigation, specifically, there are four different periods: the first is before Iran nuclear sanction on $1^{\text {st }}$ April 2012, the second is from the beginning of these sanctions until Join Comprehensive Plan of Action (JCPOA) establishment on $14^{\text {th }}$ July 2015 , the third is after JCPOA until the United States withdrawal from this agreement on $8^{\text {th }}$ May 2018, and finally, the fourth is $8^{\text {th }}$ May 2018 to 17th February 2020, on which the existence of COVID-19 has officially been promulgated. In this regard, the Sanction series for first and third periods is zero and for the second and fourth period are one 9 The prefixes of "L" and "d", respectively, represent the logarithm and first-order difference form of each variable. Moreover, to homogenize all various type of study variables, the alltime series have been standardized by the formula

( $\left.\operatorname{Standardized}\left(\mathrm{x}_{\mathrm{t}}\right)=\frac{x_{t}-\operatorname{Mean}\left(x_{t}\right)}{S D\left(x_{t}\right)}\right)$, except for the dummy variable of the study.

10 The PSI reactions to both events have not been a one-shot response, however, it was a process with several lags.

${ }^{11}$ Represented in the figures with the vertical lines. 
OIL and INF have approximately descending volatile trends. This can be construed as the direct impacts of the EXR and LQ and indirect effects of the OIL and INF on the PSI between two turning points.

It is essential to know that after the United States withdrawal from the JCPOA, with some lags, the PSI, LQ, and INF have face to a sharp increase, while the EXR and OIL have a turbulent augmentation. It seems that USA withdrawal from the JCPOA brings about oscillation in the exchange rate, Iran oil price, as well as petroleum one. These graphs demonstrate, elegantly and implicitly, the reflection of international sanctions on the research variables.

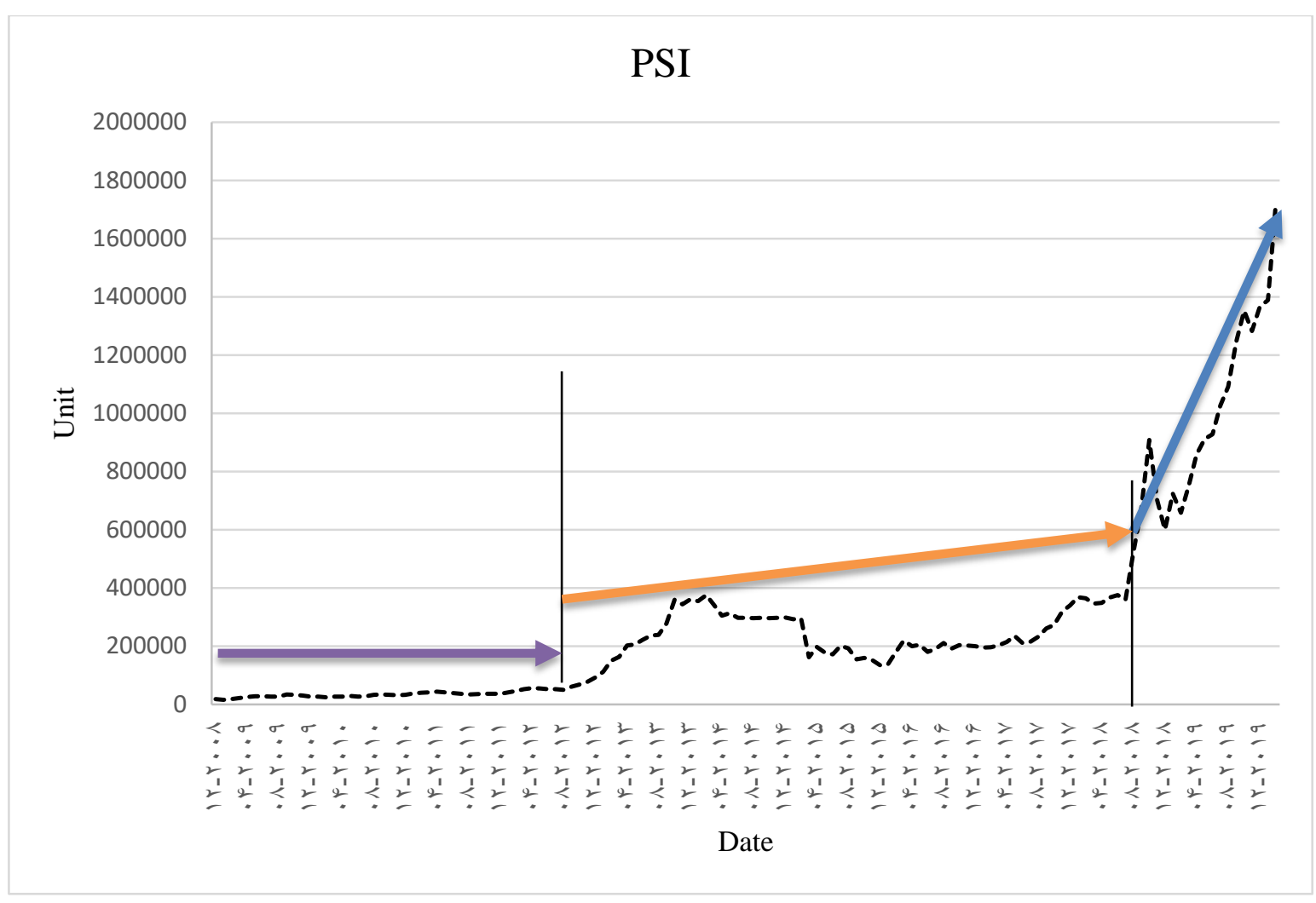

Figure 1. Time series data of the petroleum stock index 


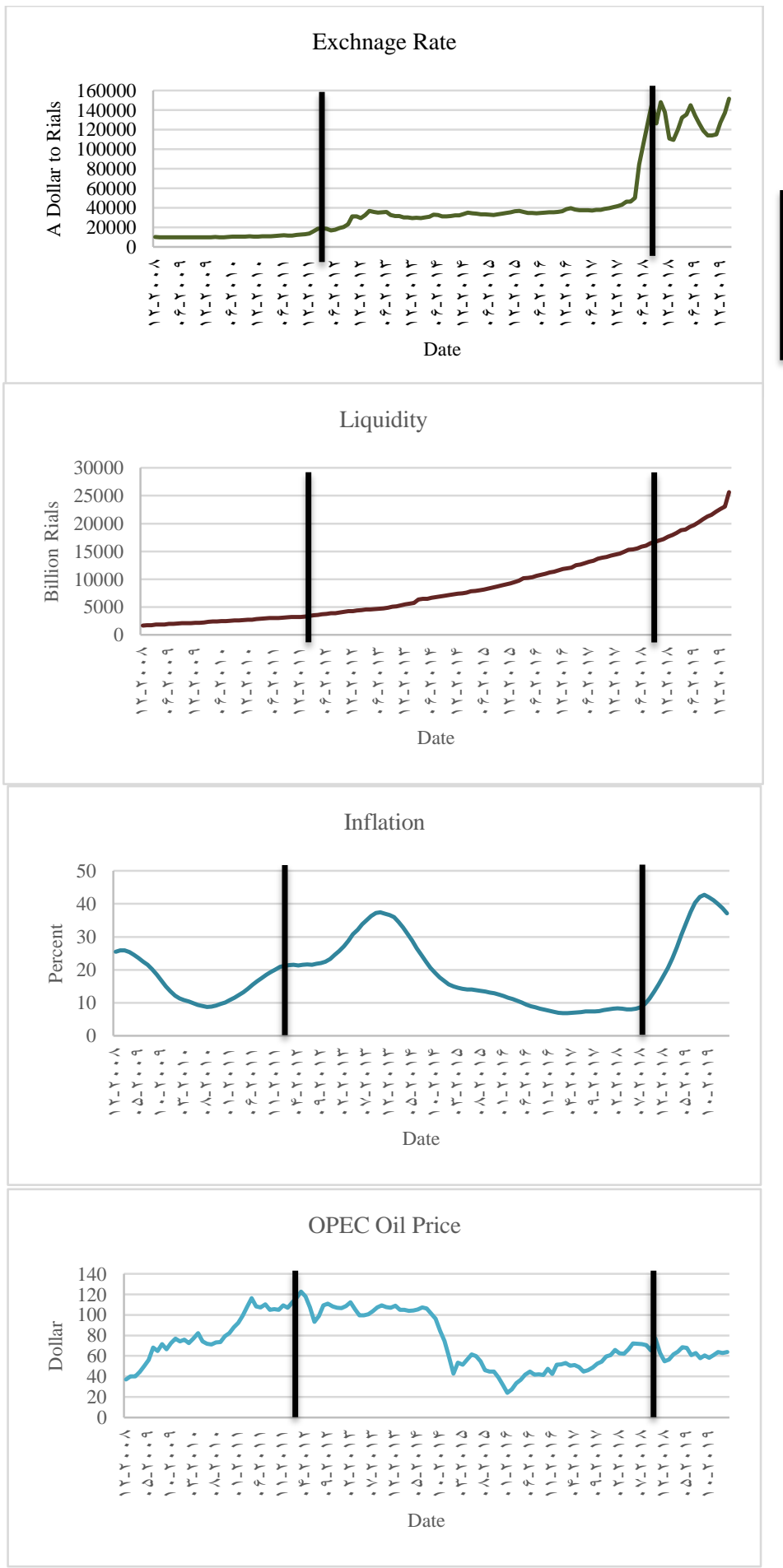

Figure 2. Time series data of the exogenous and control variables 
Ultimately, the general trend of the PSI seems to be a combination of the EXR and LQ trends, although the volatility and extreme movements of the INF and OIL are reflected on the PSI. Moreover, due to the nature and undeniable impacts of the international sanctions on different economic indicators in Iran and, accordingly, as it can be observed from the duration of the sanctions period, such shocks can be considered as one of the main factor causing turning behavior in the Petroleum Stock Index series.

Nonetheless, such a graphical analysis would not have high statistical validity; consequently, to generalize the results of the study, estimating the variable relationships seems crucial.

Considering the PSI trend, in this study, Markov-Switching model has been applied to estimate the relationship among research variables on the ground that this model gives us twofold advantages. To be more precise, meanwhile, the model renders the opportunity of estimating different framework for a separate period, i.e. regimes, based on the research variables behavior and trends, it makes a ground for comparing the impacts of the exchange rate and monetary policies on PSI and their coefficients changes from one regime to another. In line with this, the simplified form of the switching model is:

$$
\begin{aligned}
& Y_{t}=\mu\left(S_{t}\right)+\left[\sum_{i=1}^{\gamma} a_{i}\left(Y_{t-i}-\mu\left(S_{t-i}\right)\right]+u_{t}\right. \\
& u_{t} \mid S_{t}: N I D\left(0, \sigma^{2}\right), S_{t}=1,2,3, \ldots ., m
\end{aligned}
$$

In equation (1), $Y_{t}$ is the dependent variable; $S_{t}$ is the Markov-switching status variable; $Y_{t-i}$ is representative of dependent variable lags and also an independent variable vector in each regime (Arellano and Rodriguez, 2020). Indeed, in the Markov-switching model, separating periods and evaluating the relationship in that period is conducted based on the Markov chain. In such a model, on each distinctive period, the coefficients of every variable, even those of constant, are different. This contributes significantly to the more accurate and efficient research results for generalization to other assorted times owing to the fact that various events are recognized by the Markov Regime switching model, and through different regimes, the relationship between independent and dependent variables is explained. In other words, instead of determining a relationship for the whole research period, there are at least two statistically separate models (Catania and Mari, 2020). In such a circumstance, the expected duration for each of the two distinct models and their transition probabilities in different states estimate as a state transition probability matrix. 
To be more precise, this matrix presents the transition probabilities of each regime to others together with expected durations of each regime. If we consider $\mathbf{J}$ as current state probability (depends on the previous situation), then the function of the state transition probability matrix is as follow ${ }^{12}$ :

$$
P\left(S_{t}=j \mid S_{t-1}=j, \ldots\right)=P\left(S_{t}=j \mid S_{t-1}=j\right)=P_{i j}
$$

In this function, $P_{i j}$ represents the probability of a state, $\mathrm{j}$, that is located in the current period considering that the process was in state $\mathrm{i}$ in the previous period (Hayat and Katz, 2019).

\section{Results}

\section{Pre-Modelling Tests}

Before estimating the Markov Regime switching model, two groups of actions will be done: the unit root and nonlinearity tests. Avoiding the spurious regression trap, the augmented Dicky-Fuller unit root test has been used on all research variables, seen in the table (1). The results of this test demonstrate that all variables are first difference integrated (or I(1)) ${ }^{13}$, except for international sanctions, which is a dummy variable and stationary in level. On this basis, through modelling, the first difference of nonstationary data (instead of the level amounts of them) will be applied.

Table 1. Unit Root Test Results

\begin{tabular}{|c|c|c|c|c|c|}
\hline \multirow[b]{2}{*}{ Variables } & \multicolumn{3}{|c|}{ Level } & \multirow{2}{*}{$\begin{array}{c}\text { The First } \\
\text { Difference } \\
\begin{array}{c}\text { No Intercept and } \\
\text { Trend }\end{array}\end{array}$} & \multirow[b]{2}{*}{ Results } \\
\hline & $\begin{array}{l}\text { No Intercept } \\
\text { and Trend }\end{array}$ & $\begin{array}{c}\text { With } \\
\text { Intercept and } \\
\text { No Trend }\end{array}$ & $\begin{array}{c}\text { With } \\
\text { Intercept and } \\
\text { Trend }\end{array}$ & & \\
\hline LPSI & $-0.277(0.584)$ & $-0.241(0.929)$ & $-1.375(0.863)$ & $-9.816(0.000)$ & $\mathrm{I}(1)$ \\
\hline LEXR & $-0.255(0.592)$ & $-0.191(0.935)$ & $-2.248(0.459)$ & $-7.514(0.000)$ & $\mathrm{I}(1)$ \\
\hline LLQ & $0.134(0.723)$ & $-0.428(0.899)$ & $-2.069(0.557)$ & $-6.813(0.000)$ & $\mathrm{I}(1)$ \\
\hline LINF & $-0.192(0.843)$ & $-0.569(0.718)$ & $-1.321(0.752)$ & $-3.236(0.001)$ & $\mathrm{I}(1)$ \\
\hline LOIL & $-0.204(0.425)$ & $-2.018(0.281)$ & $-2.661(0.255)$ & $-9.412(0.000)$ & $\mathrm{I}(1)$ \\
\hline $\mathrm{S}$ & $-8.859(0.000)$ & - & - & - & $\mathrm{I}(0)$ \\
\hline
\end{tabular}

*The numbers in the parentheses illustrate the probability of pertinent condition occurrences. The study findings

${ }^{12}$ See [Noorani et al (2021); Guo and Ching (2021); Just and Echaust (2020); Arellano and Rodriguez (2020); Catania and Mari (2020); Hayat and Katz (2019)]

${ }^{13}$ Therefore, to ensure the accuracy of the estimated Markov Regime Switching Model and, also, to avoid the possibility of spurious regression, the first difference of all the I (1) variables (or its return) consider in the modelling process. 
After checking the stationarity test, to scrutinize the nonlinear behavior of the LPSI, firstly, a univariate autoregressive moving average model, ARIMA ${ }^{14}$, is evaluated. Secondly, the nonlinearity tests, (BDS, ARCH, McLeod-Lee, and Ramsay), have been done on the residuals of the optimum ARIMA model and results of these tests are reported in the table (2).

Table 2. Nonlinearity Test of the dLPSI

\begin{tabular}{|c|c|c|c|c|c|}
\hline Tests & \multicolumn{2}{|c|}{ Statistics (Prob.) } & Tests & \multicolumn{2}{|c|}{ Statistics (Prob.) } \\
\hline \multirow{4}{*}{ BDS } & 2 & $0.031(0.000)$ & \multirow{4}{*}{ McLeod-Lee } & 1 & $1.965(0.161)$ \\
\hline & 3 & $0.061(0.000)$ & & 5 & $2.457(0.783)$ \\
\hline & 4 & $0.074(0.000)$ & & 10 & $5.114(0.883)$ \\
\hline & 5 & $0.073(0.000)$ & & 20 & $9.633(0.974)$ \\
\hline \multirow[b]{2}{*}{$\mathrm{ARCH}$} & $\mathrm{F}$ & $1.911(0.169)$ & \multirow[b]{2}{*}{ Ramsay } & $\mathrm{F}$ & $1.612(0.203)$ \\
\hline & $\left|R^{2}\right|$ & $1.912(0.167)$ & & $\begin{array}{c}\text { Likelihood } \\
\text { Ratio }\end{array}$ & $2.512(0.285)$ \\
\hline
\end{tabular}

The study findings

The table above illustrates that the non-parametric BDS test null hypothesis ${ }^{15}$, which is applied in various dimensions from 2 to 5 , are rejected; consequently, it could be an indirect sign of nonlinearity (To know more about the details of this test see Matila-Garcia et al. (2005); Akintunde ei al (2015); Coronado et al. (2018)). Compatible with the results of BDS, the results of the RESET Ramsay test, which examine regression specification error and nonlinearity of a series, corroborate the nonlinear behavior in the LPSI. Moreover, the ARCH and McLeod-Lee tests findings indicate that there is neither heteroscedasticity nor inherent nonlinearity between the residuals of the ARIMA model. Overall, considering the results of BDS, RESET Ramsay, ARCH and McLeod-Lee tests, the LPSI has a nonlinear trend; consequently, applying the nonlinear approach, i.e. the Markov Regime Switching model, would be cogent to accurately model the LPSI behavior.

\section{Markov-Switching Model}

Following the results of pre-modelling tests, the optimal numbers of regimes should be determined before reporting the final results of the Markov Regime Switching model. To achieve this, the maximum Log-Likelihood Ratio

\footnotetext{
${ }^{14}$ The numbers of AR and Ma are determined through the ACF and PACF. Then, among the different combination of the ARIMA model, with 1 to $3 \mathrm{AR}$ and MA, the best one is recognized by the SIC and ACI information criteria. In line with this, the $\operatorname{ARIMA}(1,1,2)$ has the least estimation errors.

${ }^{15} \mathrm{~T}$ data is independently and identically distributed (i.i.d) against an unspecified alternative of nonlinearity.
} 
(or Wald test) has been used so that in the test, the probability of each estimated coefficients and finally the whole models will be probed by $\chi^{2}$ Fstatistics criteria.

Table 3. The Log-Likelihood Ratio Test Results

\begin{tabular}{|c|c|c|c|c|c|c|c|}
\hline Criteria & Value & d.f. & Probability & Criteria & Value & d.f. & Probability \\
\hline Two Regims & \multicolumn{5}{c|}{ Four Regims } \\
\hline F & 75.391 & $(18,112)$ & 0.000 & F & 210.014 & $(36,88)$ & 0.000 \\
\hline$\chi^{2}$ & 1357.039 & 18 & 0.000 & $\chi^{2}$ & 2618.983 & 36 & 0.000 \\
\hline AIC & -1.948 & SIB & -1.511 & AIC & -2.801 & SIB & -1.753 \\
\hline \multicolumn{6}{|c|}{ Three Regims } \\
\hline F & 233.642 & $(27,99)$ & 0.000 & F & 174.877 & $(45,77)$ & 0.000 \\
\hline$\chi^{2}$ & 3218.156 & 27 & 0.000 & $\chi^{2}$ & 1104.758 & 45 & 0.000 \\
\hline AIC & -3.041 & SIB & -2.319 & AIC & -1.361 & SIB & -1.273 \\
\hline
\end{tabular}

The study findings

According to table 3, it can be seen that all four estimated Markov Regime Switching models, with 2 to 5 regimes, are significant. In contrast, the model with three different regimes is of the least estimated errors ${ }^{16}$. In line with this, the results of optimum Markov Regime Switching model are as following:

Table 4. The Results of Estimated Switching-Markov Model for the dLPSI

\begin{tabular}{|c|c|c|c|c|c|c|}
\hline \multirow{2}{*}{ Variables } & \multicolumn{2}{|c|}{ The First Regime } & \multicolumn{2}{c|}{ The Second Regime } & \multicolumn{2}{c|}{ The Third Regime } \\
\cline { 2 - 7 } & $\begin{array}{c}\text { Coefficie } \\
\text { nts }\end{array}$ & Z-Statistics & $\begin{array}{c}\text { Coefficie } \\
\text { nts }\end{array}$ & Z-Statistics & $\begin{array}{c}\text { Coefficie } \\
\text { nts }\end{array}$ & Z-Statistics \\
\hline dLEXR & 0.4296 & $5.689^{*}$ & 0.6112 & $8.439^{*}$ & 0.7462 & $4.118^{*}$ \\
\hline dLLQ & 0.5509 & $6.456^{*}$ & 0.6486 & $8.554^{*}$ & 0.7872 & $5.219^{*}$ \\
\hline dLINF & 0.3299 & $3.712^{*}$ & 0.5307 & $4.186^{*}$ & 0.6494 & $2.335^{*}$ \\
\hline dLOIL & -0.7948 & $-7.097^{*}$ & -0.6721 & $-6.368^{*}$ & -0.5041 & $-3.765^{*}$ \\
\hline S & 0.3749 & $4.296^{*}$ & 0.4378 & $6.022^{*}$ & 0.6132 & $5.789^{*}$ \\
\hline C & 0.0151 & $1.843^{* *}$ & 0.1378 & $1.435^{* * *}$ & 0.1378 & $1.765^{* * *}$ \\
\hline AR(1) & -0.8427 & $5.353^{*}$ & -0.2813 & $4.295^{*}$ & 0.6601 & $11.013^{*}$ \\
\hline Log(Sigma) & -2.8888 & $-4.786^{*}$ & -3.7318 & $-3.269^{*}$ & -8.6952 & $-3.993^{*}$ \\
\hline \hline
\end{tabular}

\footnotetext{
${ }^{16}$ In addition to comparing the $\chi^{2}$ and $\mathrm{F}$ statistics, the various sorts of Markov Regime switching are also considered and based on information criteria, the best status has been recognized. To be more precise, the optimum Markov-switching model for each regime is MSIAH-AR(1). It should be noted that the variances of each regime distinctive from the other ones, and there is no heteroscedasticity in a given regime. Therefore, this finding does not contradict with the results of ARCH and McLead-Lee tests.
} 


\begin{tabular}{|c|c|c|c|}
\hline DW & & \multicolumn{2}{|c|}{2.01147} \\
\hline Ljung-Box (5) & & \multicolumn{2}{|c|}{$4.5543(0.336)$} \\
\hline McLeod-Li (5) & & \multicolumn{2}{|c|}{$0.3854(0.996)$} \\
\hline \multicolumn{4}{|c|}{ Constant transition probabilities } \\
\hline Pij & \multicolumn{3}{|c|}{$\mathrm{i}$} \\
\hline $\mathrm{J}$ & 1 & 2 & 3 \\
\hline 1 & 0.17658 & 0.79339 & 0.03003 \\
\hline 2 & 0.26036 & 0.44903 & 0.29061 \\
\hline 3 & 0.04817 & 0.60702 & 0.34481 \\
\hline \multicolumn{4}{|c|}{ Constant expected durations } \\
\hline 1 & \multirow{2}{*}{$\frac{2}{27.352016}$} & \multicolumn{2}{|c|}{3} \\
\hline 14.837919 & & \multicolumn{2}{|c|}{9.647263} \\
\hline
\end{tabular}

$*$, **, and $* * *$, respectively, represent $99 \%, 95 \%$, and less than or equal to $90 \%$ significance level. The study findings

Due to the results of the estimated Markov-Switching model, it can be stated that except for intercepts, all research variable coefficients are significant (with 95 to 99 percent confidence interval). Furthermore, both Durbin-Watson and Ljung-Box tests on the residuals of the estimated model corroborate that there is no autocorrelation between different lags of the residuals. The McLeod-Lee test, also, shows there is not any significant nonlinear relationship between the residuals (or precisely, any second power relationship between different residuals). Moreover, the significance of $\log ($ Sigma $)$, which calculates the logarithms of volatilities for each estimated regime, confirms the variance of each regime is varied from those of the other regimes. Hence, it is crucial to consider different variance for each regime to have accurate estimation results.

When it comes to the estimated coefficients, some pivotal points should be stated. First of all, the amount of the dLEXR influence on the dLPSI has augmented from the first regime, 0.43 , to the third one, 0.75 . In line with this, the impacts of monetary policy on the dLPSI have the same direction as dLEXR does so that at first to the third regime, the dLLQ coefficients are 0.55 , 0.65 , and 0.79 , respectively. In the meanwhile, although the dLINF have the direct relationship, like the exchange rate and monetary policies, with the dLPSI in all regimes, the amounts of this variable effectiveness on the dLPSI is lower than both dLEXR and dLLQ in each regime. It is a fascination to know that the effects of international sanctions on the dLPSI, from the first to the third one, has been directly increasing. Furthermore, this finding proves that the sanctions give rise to an increase in the petroleum stock index. Besides, 
concerning the AR coefficients ${ }^{17}$, at first and second regimes, they are negative, while in the third regime, it is positive. This phenomenon substantiated that the control variables, not distinctively put in the model, have decreased the dLPSI in first and second regimes by approximately -0.84 and 0.28 , whereas in the third regime, they have raised the dLPSI by 0.66 . Nonetheless, the OPEC oil price impacts on the dLPSI are the only variable with an indirect relationship. More precisely, through the first to the third regimes, the absolute amounts of the dLOIL coefficients have been reduced from -0.79 to -0.50 . It seems that through the research period, by prolonging international sanction, OPEC oil price effectiveness on Iran's petroleum stock price has weakened especially in the third regime. To sum up, the relationship between the dLEXR, dLLQ, dLINF, S and dLPSI, in each of three regimes, are positive, while the coefficients of the dLOIL, in all determined regimes, is negative. In other words, although the coefficients of each independent variable have changed from one regime to another, the stable direction of the relationship can be seen through all three regimes.

Regarding the transition probability from one regime to the others and the duration of each regime, it can be stated that the probability of the second regime is higher than the two others. Accordingly, the duration of the second regime is around 27 months, while those of the first and third are, in order, roughly 15 and 10 months. All this evidence corroborate that the probability of the second regime is more likely.

\section{Conclusion}

The primary purposes of this investigation are comparing the effects of exchange rate movements and monetary policies on the petroleum industry stock index in the TSE. It is examined by Markov Regime Switching model in the period from December 2008 to February 2020 together with considering OPEC oil price, inflation rate, and international sanctions as the control variables. Furthermore, tracing the historical roots of changes in the PSI behavior, regimes, and the relationships between the exogenous variables and the PSI is another purpose of this study. Regarding the critical objective of the research and based on theoretical frameworks, hypotheses have been introduced, all of which are accepted. As official statistics and empirical evidence of Iran economy demonstrate, both monetary policies and exchange

${ }^{17}$ The representative of all effective variable on the dLPSI that are not included separately in the model. 
rate movements have positively affected the petroleum stock index returns. Moreover, the impacts of monetary policies are awhile more than those of exchange rate movements in all three estimated regimes of the Markov Regime Switching model. It is the same for inflation rate and international sanctions relationship with the dLPSI as an export-oriented industry. However, the OPEC oil price has negatively affected the returns of petroleum stock index. In the following, the results of Markov Regime Switching regimes will be more specifically dissected.

In terms of the exchange rate, it directly, and increasingly, affects the dLPSI through first to third regimes. This finding consistent with Durnbusch and Fisher (1980) The flow-oriented model, while it is in contrast to both Branson et al. (1983) and Frankel (1983) stock model. These findings illustrate that under the growing international sanction pressure, the role of the exchange rate on the dLPSI movements has been enlarged so that at the third regime, it approximately reaches to the 0.75 . the reason behind the positive relationship of the exchange rate is rooted in the export-oriented nature of the petroleum industry. To clarify, when the exchange rate enhances it generally means that the national currency is devaluated; consequently, this can also be interpreted as a reason of an increase in the export possibility of petroleum industry products which are among the high demand export-oriented goods in the international arena. Thus, the profitability of petroleum companies, and subsequently, their stock prices will logically be augmented. This way, an increase in the exchange rate can give a significant rise to an augmentation in petroleum stock price.

When it comes to the impacts of monetary policies (the liquidity volume), it, as well as the exchange rate, has positively changed the dLPSI. The findings substantiate that the impacts of liquidity volume on the petroleum stock index return have been increasing throughout all three separated regimes. This result has been corroborated by Monetarism and Keynesians, whereas it is contrary to Fama (1981) and Fridman (1956) standpoints. Since the most hitherto implemented monetary policies in Iran are expansionary, and through the money issuance, the impacts of these policies on the export-oriented petroleum industry have been realized through national currency devaluation channel (exchange rate growth) and relative prices reduction of exported goods. In fact, monetary policies have influenced the returns of petroleum stock index through adjusting inflation and exchange rate. That is why the effects of this variable are greater than those of the exchange and inflation rates. It should be noted that after imposing oil and petroleum embargos on Iran in April 2018, roughly the third regime, the reason of LPSI increase has not been dominantly pertinent 
to the petroleum export and profit growth of such companies. However, it has been mostly rooted in the money issuance (imposed by the twelfth government of Iran) due to compensating the budget deficit caused by remarkably reduced oil revenues as a result of various international sanctions especially the "Maximum Pressure" one. This phenomenon brings about hyperinflation in Iran so far that roughly all nominal prices have been exponentially surged from which petroleum stock index has not been exempted.

Despite the exchange rate, monetary policies, inflation, and international sanctions direct effects on the dLPSI, OPEC Oil Price has indirectly influenced the petroleum stock index returns. An interesting point here is that from the first to the third regimes, the effects of OPEC Oil price on the dLPSI has gradually dwindled. The reason behind the decrease in the role of OPEC oil price comes back to imposing the international sanctions on Iran oil and petroleum exports during the research period. Moreover, being row material of petroleum products, it is verifiable that the OPEC oil price has negative impacts on the petroleum stock index returns. In other words, increasing of OPEC oil price leads to augment Iran oil price, as the petroleum row material, ergo the production cost of petroleum would be enlarged by each growth of OPEC oil price. This way, by an increase in OPEC oil price, the profitability of petroleum companies and their stock returns would significantly decline.

Ultimately, comparing the results of this study with the literature support the idea that there are more some new findings as to the contributions of the study. First and foremost, applying Markov Regime Switching model in which the relationship between the variables is separated based on the dependent variable structural breakpoints, could give us a more accurate estimation and more in-depth insight into the reality of Iran economy. Directly speaking, in the research period, the dLPSI has statistically two turning points (or three different regimes) that can historically be attributed to "Iran nuclear sanction on April 1 2012" and "the United States withdrawal from this agreement on May 8 2018". Compatibility of the model regime numbers with the historical events of the international sanctions can tangibly emphasize the accuracy of the model and how precisely the Markov-Switching approach can delineate the effects of international sanctions reflected on the dLPSI. Furthermore, not only does the model could consider actual historical events of Iran economy through regimes, but it could depict the changing reaction of dLPSI to exchange rate, monetary policies, and other control variables from one regime to the others as well. Specifically, this point refers to nonlinear and different effects of the independent variables on dLPSI from one regime to another. 
According to the research results, some practical suggestions could be stated for three groups of economic members; PSI managers, stock market investors, and policymakers. From the PSI managers' standpoint, in turbulent economic conditions, like the third regime, they can catch fish in muddy water. To be more precise, when the exchange rate, liquidity volume, inflation rate and sanctions have increased, the PSI managers can increase their international sales and consequently companies' profits. This strategy works for stock market investors as well. However, for economic policymakers, policy depends on their targets. In other words, if they are decided to raise the PSI, they should adopt expansionary monetary policies and vice versa.

Although the findings of the investigation have been fascinating, there has been some study limitation. Firstly, quantifying the international sanctions has been so hard since the sanctions are a non-numerical historical event. Secondly, many control variables cannot be entered in the estimated model because of the regression model restrictions, like collinearity. Thirdly, the frequency of time series data was the other limitation. In fact, two of the variables, LQ and INF, frequencies were monthly, while the others were daily. Finally, the period of the data was limited to December 2008 to February 2020 due to the fact that some data have not available before December 2008 and also, the promulgation of COVID-19 had occurred in February 2020. Hence the changing in the relationship of the variables, after February 2020, could not be completely attributed to the monetary and exchange rate policies.

Based on the study results together with the study limitations, it is highly recommended applying general equilibrium models for more accurate modelling the effects of monetary and exchange rate policies on PSI for two main reasons. The first, regression models have some structural restrictions rendering the results occurred in a certain circumstance. The second, the general equilibrium models consider whole essential parts of the economy and present the impulse and response under the real economic conditions. The other suggested investigation could be done about the relationship among these study variables after COVID-19.

Funding: This research received no external funding. 


\section{References}

Abbasi, Gh.R., Mohammadi, H., Mohammadi, O., Mohammadpour Ch. (2015). The Study of the Effects of Exchange Rate Fluctuations on Petrochemical Industry Return in Tehran Stock Exchange. European Online Journal of Natural and Social Sciences: Proceedings. 4(1). 1170-1179.

Akintunde, M.O., Oyekunle, J.O., Olalude G.A. (2015). Detection of Nonlinearity in the Time Series Using BDS Test. Science Journal of Applied Mathematics and Statistics, 3(4), 184-187.

Ansari, M.G., Sensarma, R. (2019). US monetary policy, oil and gold prices: Which has a greater impact on BRICS stock markets? Economic Analysis and Policy, 64, 130-151.

Arellano, M.A., Rodriguez, G. (2020). Empirical modeling of high-income and emerging stock and Forex market return volatility using Markov-switching GARCH models. North American Journal of Economics and Finance, 52, 1-18.

Bahmani-Oskooee, M., Saha, S. (2016). Do exchange rate changes have symmetric or asymmetric effects on stock prices? Global Finance Journal, 31, 57-72

Basher, S. A. \& Alfred, A. H. \& Sadorsky, P. (2012). Oil prices, exchange rates and emerging stock markets, Energy Economics, 34(1), 227-240.

Bermudez Delgado, N.A., Bermudez Delgado, E., Saucedo, E. (2018). The relationship between oil prices, the stock market and the exchange rate: Evidence from Mexico. The North American Journal of Economics and Finance, 45, 266-275.

Bernanke, B. S., \& Gertler, M. (1995). Inside the black box: the credit channel of monetary policy transmission. Journal of Economic Perspectives, 9, 27-48.

Bjornland, H.C., Leitemo, K. (2009). Identifying the interdependence between US monetary policy and the stock market. Journal of Monetary Economics. 56(2), 275-282.

Branson, W. H. (1983). Macroeconomic determinants of real exchange rates. Working paper No. 801, Cambridge, UK: The National Bureau of Economic Research.

Catania, L., Mari, R.D. (2020). Hierarchical Markov-switching models for multivariate integer-valued time-series. Journal of Econometrics, Available Online, March 13, 1-20.

Challe, E., Giannitsarou, C. (2014). Stock prices and monetary policy shocks: A general equilibrium approach. Journal of Economic Dynamics and Control, 40, 46-66.

Chami, R., Cosimano, T.F., Fullenkamp, C. (1999). The Stock Market Channel of Monetary Policy. IMF Working Paper. International Monetary Fund WP/99/22.

Chao, C.C., Hu, S.W., Tai, M.Y., Wang, V. (2011). Monetary policy 
announcements and stock price dynamics in a small open economy. International Review of Economics \& Finance, 20(4), 520-531.

Chatziantoniou, I., Duffy, D., Filis, G. (2013). Stock market response to monetary and fiscal policy shocks multi-country evidence. Economic Modelling. 30, 754-769.

Cloyne, J., Ferreira, C., Surico, P. (2020). Monetary Policy when Households have Debt: New Evidence on the Transmission Mechanism. The Review of Economic Studies, 87(1), 102-129.

Coronado, S., Jimenez-Rodrguez, R., Rojas, O. (2018). An Empirical Analysis of the Relationships between Crude Oil, Gold and Stock Markets. The Energy Journal, 39(11), 193-207.

Dahmene, M., Boughrara, A., Slim, S. (2021). Nonlinearity in stock returns: Do risk aversion, investor sentiment and, monetary policy shocks matter? International Review of Economics \& Finance, 71, 676-699.

Dornbusch, R., \& Fischer, S. (1980). Exchange rates and the current account. The American Economic Review, 70(1), 960-971.

Fama, E. (1981). Stock returns, real activity: inflation and money. The American Economic Review. 71(4), 545-565.

Fama, E. F. (1990). Stock Returns, Expected Returns, and Real Activity." The Journal of Finance. 45 (4). 1089-1108.

Frankel, J. (1983). Monetary and portfolio balance models of exchange rate determination. Edited by J. Bhandari and B. Putnam (Eds.), In Economic interdependence and flexible exchange rates 84-115. Cambridge, MA: MIT Press.

Friedman, M. (1956). The Quantity Theory of Money-A Restatement, Reprinted from Studies in the Quantity Theory of Money. University of Chicago Press.

Gong, P., Dai, J. (2017). Monetary policy, exchange rate fluctuation, and herding behavior in the stock market. Journal of Business Research. 76. 34-43.

Guo, S., Ching, W.K. (2021). High-order Markov-switching portfolio selection with capital gain tax. Expert System with Applications, 165, 1-13.

Hajiebrahimi Farashah, V., Hosseini, S.H., Sazvar, Z., Shakouri Ganjavi, H. (2020). An investigation on the petrochemical industry development in Iran: a system dynamics approach. International Journal of Energy Technology and Policy. 16(5-6). 109-121.

Hayat, A., Katz, Ph. (2019). Investigating the Presence of a Nonlinear Exchange Rate Pass-Through: A Markov Switching Model Approach. Journal of Advances in Economics and Finance, 4(1), 29-37.

Heidari, H., Refah Kahriz, A. Mohammadzadeh, Y. (2019). Stock market 
behavior of the pharmaceutical industry in Iran and macroeconomic factors. Economic Change Restrictions, 52, 255-277.

Honarmandi, Z., Sepasi, S., Azar, A. (2019). Comparing the Impact of Brand Value on Corporate Profit in B2B and B2C Businesses: A Case Study. Iranian Journal of Management Studies, 12(1). 121-147.

Hsueh, H.P., Li, F., Liu, Ch. (2020). Analysis of the Linkage between South African's Exchange Rate and Stock Price Index. Journal of Physics: Conference Series, 1621, 1-7.

Ioannidis, C., Kontonikas, A. (2007). The impact of monetary policy on stock prices. Journal of Policy Model. 30, 33-53.

Jung, Y.C., Dasa, A., McFarlane, A. (2019). The asymmetric relationship between the oil price and the US-Canada exchange rate. The Quarterly Review of Economics and Finance, 76, 198-206.

Just, M., Echaust, K. (2020). Stock market returns, volatility, correlation and liquidity during the COVID-19 crisis: Evidence from the Markov switching approach. Finance Research Letters, Available Online, September 28.

Khosrowzadeh, A., Alirezaei, A., Tehrani, R., Hashemzadeh Khourasgani, Gh. (2020). Does Exchange Rate Nonlinear Movements Matter for Analyzing Investment Risk? Evidence from Investing in Iran's Petrochemical Industry. Advances in Mathematical Finance and Applications, 5(1), 11-28.

Komijani, A., Gandali Alikhani, N., Naderi Abbandani, E. (2013). The Long-run and Short-run Effects of Crude Oil Price on Methanol Market in Iran. International Journal of Energy Economics and Policy, Econjournals, 3(1), 43-50.

Kurov, A., Stan, R. (2018). Monetary policy uncertainty and the market reaction to macroeconomic news. Journal of Banking \& Finance, 86, 127-142.

Laopodis, N. T. (2013). Monetary policy and stock market dynamics across monetary regimes. Journal of International Money Finance, 33, 381-406.

Matilla-Garcia, M., Sanz, P., Vazquez, F.J. (2005). The BDS test and delay time. Applied Economics Letter, 12(2), 109-113.

Mishkin, F. (2001). The transmission mechanism and the role of asset prices. Monetary Policy Working Paper, No. 8617. http://www.nber.org/papers/w8617.

Noorani, I., Mehrdoust, F., Nasroallah, A. (2021). A generalized antithetic variates Monte-Carlo simulation method for pricing of Asian option in a Markov regime-switching model. Mathematics and Computers in Simulation, 181, 1-15.

Olli-Matti, L. (2020). Monetary policy and stock market valuation, Bank of Finland Research Discussion Papers, Series number16/2020, ISBN: 978-952-323348-5. 
Phylaktis, K. \& Ravazzolo F. (2005). Stock prices and exchange rate dynamics, Journal of International Money and Finance, 24(7), 1031-1053.

Ricci, O. (2015). The impact of monetary policy announcements on the stock price of large European banks during the financial crisis. Journal of Banking \& Finance, 52, 245-255.

Ross, S. A. (1976). The Arbitrage Theory of Capital Asset Pricing. Journal of Economic Theory 13.341-360.

Saadati, A., Honarmandi, Z., Zarei, S. (2020). Real Exchange Rate Shocks and Export-Oriented Businesses in Iran: An Empirical Analysis Using NARDL Model. Munich Personal RePEc Archive (MPRA) Working Paper, the Munich University Library in Germany, No. 101554.

Salisu, A.A., Isah, K., Ogbonnaya-Orji, N. (2020). A firm-level analysis of the asymmetric response of U.S. stock returns to exchange rate movements. International Journal of Finance and Economics, In Press, https://doi.org/10.1002/ijfe.2210

Shavvalpour, S., Khanjarpanah, H., Zamani, F., Jabbarzadeh. A. (2017). Petrochemical Products Market and Stock Market Returns Empirical Evidence from Tehran Stock Exchange. Iranian Economic Review. 21(2), 383-403.

Singhal, S., Choudhary, S., Biswal, P.C. (2019). Return and volatility linkages among International crude oil price, gold price, exchange rate and stock markets: Evidence from Mexico. Resources Policy, 60, 255-261.

Suhaibua, I., Harvey, S.K., Amidub, M. (2017). The impact of monetary policy on stock market performance: Evidence from twelve (12) African countries. Research in International Business and Finance. 42. 1372-1382.

Thanh, S.D., Canh, N.P., Maiti, M. (2020). Asymmetric effects of unanticipated monetary shocks on stock prices: Emerging market evidence. Economic Analysis and Policy, 65, 40-55.

Tiryaki, A., Ceylan, R., Erdogan, L. (2019). Asymmetric effects of industrial production, money supply and exchange rate changes on stock returns in Turkey, Applied Economics, 51(20), 1-13.

Tiryaki, A., Ceylan, R., Erdoğan, L. (2020). Asymmetric effects of industrial production, money supply and exchange rate changes on stock returns in Turkey. Journal of Applied Economics. 51(20). 2143-2154.

WooPark, K., Hong, d., JimmyOh, J.Y. (2019). Investor behavior around monetary policy announcements: Evidence from the Korean stock market, Finance Research Letters, 28, 355-362.

Yola, A.N.T. (2019). On the Reaction of Stock Market to Monetary Policy Innovations: New Evidence from Nigeria, Academic Journal of Economic Studies, 5(2), 94-98. 
Zarei, S. (2020). Analyzing the Asymmetric Effects of Inflation and Exchange Rate Misalignments on the Petrochemical Stock index: The Case of Iran. Munich Personal RePEc Archive (MPRA) Working Paper, the Munich University Library in Germany, No. 99101.

Bibliographic information of this paper for citing:

Molavi Bisetoni, Shahram; Fathi Hafshejani, Kiamars; Alirezaei, Aboutorab \& Abbaspour Esfadan, Ghanbar (2021). Exchange Rate Movements and Monetary Policies: Which Has Greater Influence on Petroleum. Iranian Journal of Finance, 5(1), 147-172.

Copyright (C) 2021, Shahram Molavi Bisetoni, Kiamars Fathi Hafshejani, Aboutorab Alirezaei and Ghanbar Abbaspour Esfadan 